\title{
Organizing palliative care in the rural areas of Iran: are family physician-based approaches suitable?
}

This article was published in the following Dove Press journal: Journal of Pain Research

\author{
Hossein Jabbari' \\ Saber Azami-Aghdash ${ }^{2}$ \\ Reza Piri ${ }^{3}$ \\ Mohammad Naghavi- \\ Behzad $^{4}$ \\ Mark JM Sullman ${ }^{5}$ \\ Saeid Safiri ${ }^{6,7}$
}

'Department of Community Medicine, Tabriz University of Medical Sciences,

Tabriz, Iran; ${ }^{2}$ Iranian Center of Excellence in Health Management, School of Management and Medical Informatics, Tabriz University of Medical Sciences, Tabriz, Iran;

${ }^{3}$ Students' Research Committee, Tabriz University of Medical Sciences, Tabriz, Iran; ${ }^{4}$ Medical Philosophy and History Research Center, Tabriz University of Medical Sciences, Tabriz, Iran; ${ }^{5} \mathrm{~S} c h o o l$ of Humanities and Social Sciences, University of Nicosia, Nicosia, Cyprus; ${ }^{6}$ Managerial Epidemiology Research Center, Department of Public Health, School of Nursing and Midwifery, Maragheh University of Medical Sciences, Maragheh, Iran; ${ }^{7}$ Department of Epidemiology and Biostatistics, School of Public Health, Tehran University of Medical Sciences, Tehran, Iran

Correspondence: Saeid Safiri Managerial Epidemiology Research Center, Department of Public Health, School of Nursing and Midwifery, Maragheh University of Medical Sciences, Majles Sq., Maragheh, Iran Email saeidsafiri@gmail.com
Introduction: The provision of palliative end-of-life care (P/EOLc) for patients, wherever they live, is an increasingly important service, particularly given the increasing rates of cancer and other life-threatening diseases in Iran. However, unfortunately, those living in the rural areas of Iran are greatly disadvantaged with respect to this type of care. Therefore, the present study explored the feasibility of organizing P/EOLc in the rural areas of Iran.

Methods: In this qualitative study, two focus group (FG) discussions were held in Tabriz (Iran) with rural family physicians (FPs, $n=23)$ and key P/EOLc stakeholders $(n=13)$. The FG sessions were recorded, transcribed, and the transcriptions checked by participants before the data were subjected to content analysis.

Results: While most FPs indicated that they did not have sufficient involvement in providing $\mathrm{P} / \mathrm{EOLc}$, they emphasized the necessity of providing P/EOLc through four main themes and 25 subthemes. The four main themes were labeled as "structures and procedures," "health care provider teams," "obstacles," and "strategies or solutions." Furthermore, according to the main themes and subthemes identified here, the key stakeholders believed that the Iranian health system and the FPs' team have the potential to provide P/EOLc services in rural areas.

Conclusion: The most feasible strategy for providing P/EOLc in Iranian rural areas would be to use the current health care framework and base the process around the FP.

Keywords: palliative end-of-life care, rural areas, family physician team

\section{Introduction}

In 2016 , noncommunicable diseases accounted for $72.3 \%$ of deaths globally and this number is increasing. ${ }^{1}$ Furthermore, cancers account for a large proportion of these deaths and the number of cases increased by almost a third between 2006 and $2016 .^{2}$ During this same period, the number of cases in Iran increased by $41 \%$, although population growth and increase in life expectancy also contributed to this increase. ${ }^{3}$ This situation poses substantial challenges for the Iranian health care system, especially in terms of escalating costs, maintaining quality of care, utilization patterns of hospital beds, place of death, and dignity in death. ${ }^{4}$ Therefore, in accordance with the objectives of universal health coverage,${ }^{6}$ organizing palliative end-of-life care $(\mathrm{P} /$ EOLc) for those patients who need it (ie, they cannot be cured, based on the reports of two experts, and are expected to live no longer than 6 months) is vital, regardless of where they live or their type of disease(s). ${ }^{5}$

Palliative care, as one of the main pillars of cancer control, plays an important role in the management of patients with cancer. ${ }^{5}$ Furthermore, according to the WHO 
palliative care is "an ethical responsibility of health systems" and it should be integrated into public health care systems in line with the sustainable development goal for universal health coverage. ${ }^{7}$

In spite of the WHO recommendations, ${ }^{7}$ palliative health care is a relatively new concept in Iran. At the time of this research, P/EOLc in Iran was limited to five to six active centers in large cities without any coherent structure. ${ }^{8}$ Therefore, despite the fact that $\sim 21 \%$ of the Iranian population reside in rural areas, ${ }^{10}$ these areas have been neglected, as has been observed in other countries. ${ }^{8,9}$ However, the rural areas of Iran are under coverage of the family physician program, with common issues being caring for the elderly and chronically ill patients. ${ }^{11,12}$

According to the literature, P/EOLc is often low-cost and cost-effective, and in most cases, cost reductions were statistically significant. ${ }^{13}$ In this situation, the provision of $\mathrm{PC} /$ EOLc should be considered to be an essential service in rural communities. ${ }^{14}$ However, numerous studies have indicated that the provision of $\mathrm{P} / \mathrm{EOLc}$ to rural residences is a poorly researched topic, ${ }^{15-17}$ and there is very little information about the best way to organize, support, and deliver P/EOLc in rural areas. ${ }^{16} \mathrm{~A}$ significant number of studies have reported that palliative care for rural area is more cost-effective if delivered using extant rural health facilities or homes and involves FPs, community nurses, family, and others. ${ }^{18}$ In addition, research has found that Iranian families try hard to care for and cure their patients, especially toward the end of their life, possibly due to their Islamic beliefs and culture. They also prefer to care for their dying family members in their own home, which often results in hospitalized patients being transferred to their home when they are close to dying. In particular, family members try to emotionally support their dying relatives. ${ }^{19}$

However, any effort to provide palliative care in rural areas must begin with a clear understanding of patient preferences regarding their place of death, ${ }^{20}$ health care professionals' opinions, potential models that could be adopted, ${ }^{21}$ specific barriers, commitment from the community, ${ }^{15,22}$ the potential to integrate these services into the existing health care system, and the availability of resources, particularly sustainable funding. ${ }^{14}$ There is growing evidence regarding the central role that the FP plays in public health care services, particularly as a first point of contact for all services, including P/EOLc. ${ }^{23-25}$ Therefore, investigating the views of health care workers and the other main stakeholders will allow us to develop a more appropriate approach to $\mathrm{P} /$ EOLc. ${ }^{26}$ Therefore, the present study investigated the expe- riences and views of FPs, as well as other key stakeholders (those people who would be important for the planning, implementing, and managing $\mathrm{P} / \mathrm{EOLc}$ in the rural areas of Iran) about the feasibility of organizing P/EOLc in the rural areas of Iran.

\section{Methods}

\section{Health system of Iran}

Health care in the rural areas of Iran is provided by Health Centers, which are peripheral units of the health system in the rural areas of Iran. These centers are tasked with providing improved health outcomes, a functioning primary health care (PHC) network, countrywide coverage, an efficient hierarchy, care for an aging population, and an integrated and accessible health care service via the FP team. The health care system must also deal with the challenges posed by chronic diseases as well as practicing in the context of family and the community. ${ }^{27}$

The health care network in Iran was established in the mid-1980s and was improved in 2005, with family planning and rural health insurance reforms, and again in 2014 with the Health Sector Evolution Plan (HSEP). ${ }^{29}$ The network covers all rural residents using qualified health care teams, which consists of the FP, midwives or nurses, and behvarzes. ${ }^{30-32}$ Behvarzes are indigenous personnel who have had 2 years formal education in the health system. ${ }^{27,28}$ Each FP team is responsible for covering 3,000-4,000 people in an affordable manner and are accessible 7 days a week. Furthermore, the HSEP reform struggled to improve the quality of PHC, hospital care, reducing patients' personal costs, and to expand the coverage of basic care needs in the health insurance schema. ${ }^{29,33}$ Hence, all of the rural Iranian people have access to their FP team and their health information is kept at the Health Centers. It should also be noted that the rural residents also have access to second level (County level) and third level (Province level) care services, as well as advanced health services, through referrals made by the FP team. This referral system will be improved in the near future with the planned implementation of an electronic health record system (Figure 1). It is also important to note that the private sector does not currently have any role in health care, other than providing a small number of outpatient services.

\section{Study design, data collection, and sampling method}

The present study used a qualitative research method, in order to understand the perspectives of patients, patients' families, 


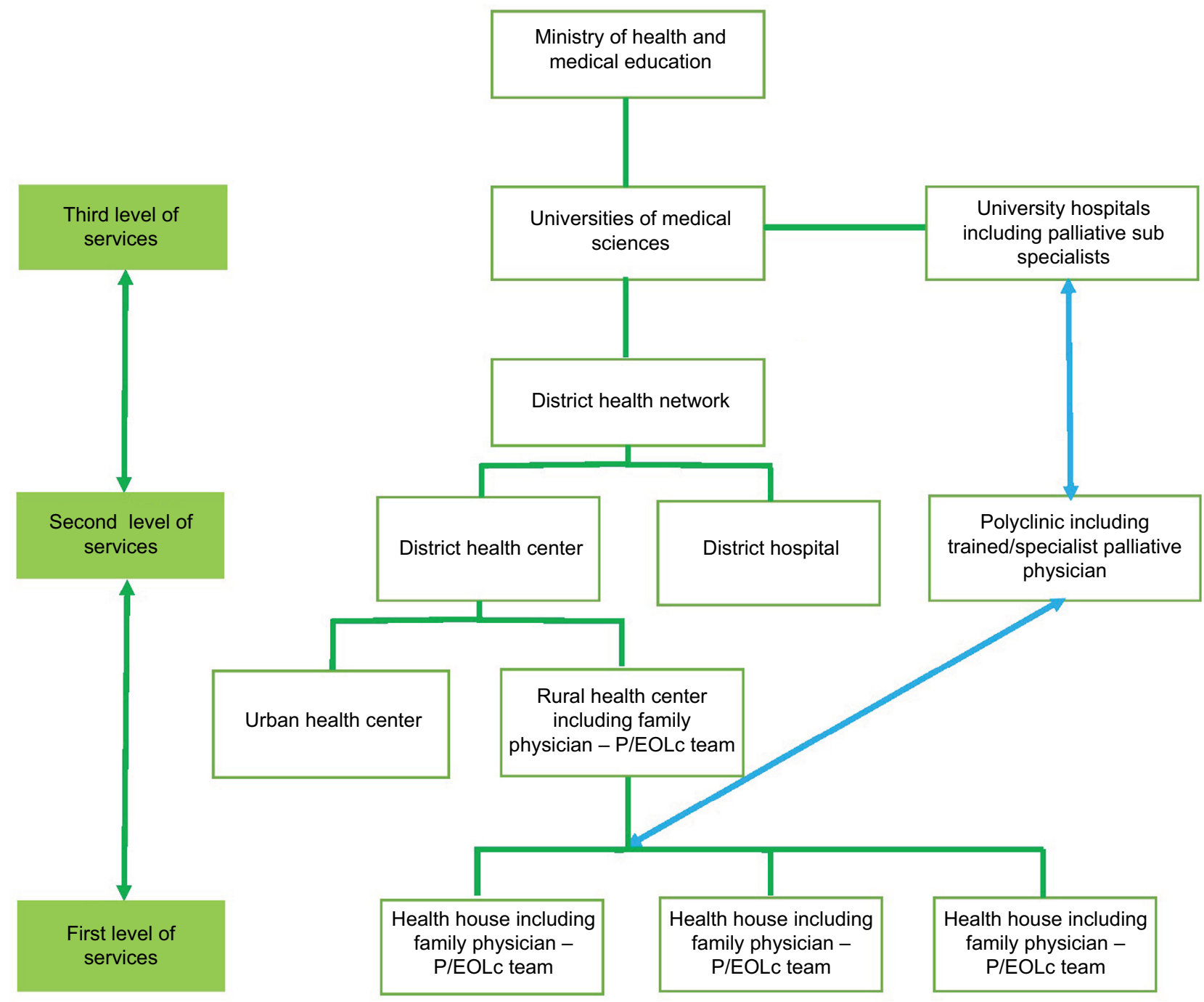

Figure I Health system of Iran and suggested model for integration of P/EOLc in this system. Abbreviation: P/EOLc, palliative end-of-life care.

and health care providers, regarding the development of $\mathrm{P} /$ EOLc services in Iran.

Two focus groups (FGs), which is a group interview to collect qualitative data on "topics" by focusing on understanding problems and identifying needs, were conducted with FPs and other key stakeholders in the P/EOLc process. The inclusion criteria for the FGs were having at least 3 years of work experience and having had a minimum of three patients who needed P/EOLc in the last 2 years. Purposive sampling was used and the participants were matched for occupation, but differed according to age, sex, and work experience. A sample of 23 physicians who were active in the study area agreed to participate and came to the Faculty of Medicine at the Tabriz University of Medical Sciences (Tabriz, Iran) to take part in a 90-minute FG. During the session, a series of questions, which had previously been developed by a team of experts using the Delphi approach, were asked and follow-up questions were also asked, depending on the participants' answers. The questions were designed to cover different dimensions of organizing P/EOLc in the rural areas of Iran.

The whole session was recorded with the participants' written approval, and the researchers also took notes during the session. Immediately following each session, the voice files were transcribed and checked (by the participants), so that no information was missed or misunderstood.

In the second FG, the main stakeholders included the Deputy of the Health Department at the Tabriz University of Medical Sciences, aging experts at the University, professors and the head of the oncology department, head of 
department and three professors of palliative medicine, the hospital head (with extensive experience of FP programs, as a head FP, 10 years in the community medicine department, as well as numerous research projects within this domain), representatives of a charity, and two professors from the health services management department with extensive experience and knowledge about FP programs (13 people in total). These participants were also selected using purposive sampling. The questions were concerned with the necessity, feasibility, and modality of organizing P/EOLc in rural areas. During the 110-minute session, the abovementioned topics were considered and the discussions were recorded, transcribed, and analyzed.

\section{Data analysis}

Content analysis was used to analyze the data, with coding of the data conducted by two independent coders. The process of analyzing and coding the data consisted of reading the transcript at least twice, developing the initial coding, identifying the initial themes, and omitting any repetitive results. This was followed by rereviewing the themes, naming and explaining the themes, and finally a discussion between the coders to clarify any differences. Data were rigorously evaluated using Lincoln and Guba's Evaluative Criteria. The credibility and transferability of the data were examined using triangulation, member checking, and thick description, respectively. Two independent coders were used to increase the dependability of the data. Finally, the transferability of the data criterion was met using expert opinion and by purposeful sampling.

\section{Ethical considerations}

All participants signed a written informed consent form and the study protocol was approved by the Ethics Committee of the Tabriz University of Medical Sciences, which was in compliance with the Declaration of Helsinki.

\section{Results}

The FPs in the first FG had between 5 and 27 years of work experience and had managed three to five P/EOLc patients in the last 2 years. Most of these physicians acknowledged that they did not have sufficient experience with end-of-life (EOL) patients. One of the physicians stated that "family doctors do not usually encounter these patients, as they are usually in hospitals or in their homes and outside of these contexts, do not get active care." Another physician stated "it is usually in this order, we validate their insurance papers to referral and that's it, we don't usually have direct contact with these patients." Most importantly, all of the participants agreed that these services were a necessity and that the public health care system has the potential to deal with this issue.

The remaining time of the first FG was dedicated to the importance of providing P/EOLc services and how to provide these services. Four main themes were extracted from the discussion about the feasibility of organizing $\mathrm{P} /$ EOLc in rural areas, which were "structures and procedures," "health care provider teams," "obstacles," and "strategies or solutions" (Figure 2). Structures and procedures theme contained material about the structures and procedures needed to provide $\mathrm{P} / \mathrm{EOLc}$ services in the rural areas of Iran. Subthemes were also extracted and the main themes are presented in Table 1, along with representative statements. FPs reported that there was a need to involve FPs, family members, and charities in a stratified referral system, which has dedicated regional centers, and a clearly defined program and registration system.

The participants suggested that the teams providing $\mathrm{P} /$ EOLc, Provider Teams, should include a FP, nurse, psychologist, family member(s), social worker, and religious person, as shown in Table 2. In fact, the members of this team are already currently responsible for P/EOLc services at the first level of the Iranian health system. Therefore, there is no need to create another structure, but there is a clear need to develop multiprofessional teams that are focused on P/EOLc and are capable of working within the Iranian health system.

The challenges related to providing $\mathrm{P} / \mathrm{EOLc}$ in rural areas, generated from the FG, are presented in Table 3 . Table 3 also presents the obstacles that the physicians commonly experienced. This part of the discussion focused on the many contextual, financial, cultural, and technical difficulties, as $\mathrm{P} / \mathrm{EOLc}$ is a relatively new concept in Iran. Participants also came up with a number of suggestions to overcome the identified problems/challenges, which included establishing palliative medicine clinics, considering new paths for $\mathrm{P} /$ EOLc patients, suggestions on how to deal with the costs, along with empowering care providers and families through the provision of appropriate training (Table 4)

The first FG, involving key people in the implementation and provision of $\mathrm{P} / \mathrm{EOLc}$ services, found that the most effective approach would be to integrate these services into the current Iranian health system, by defining specialized service packages, the selection of appropriate team members, and sustainable financing. In the second FG, the discussion questions were developed based upon the results of the previous FG involving rural family physicians, and the data were 


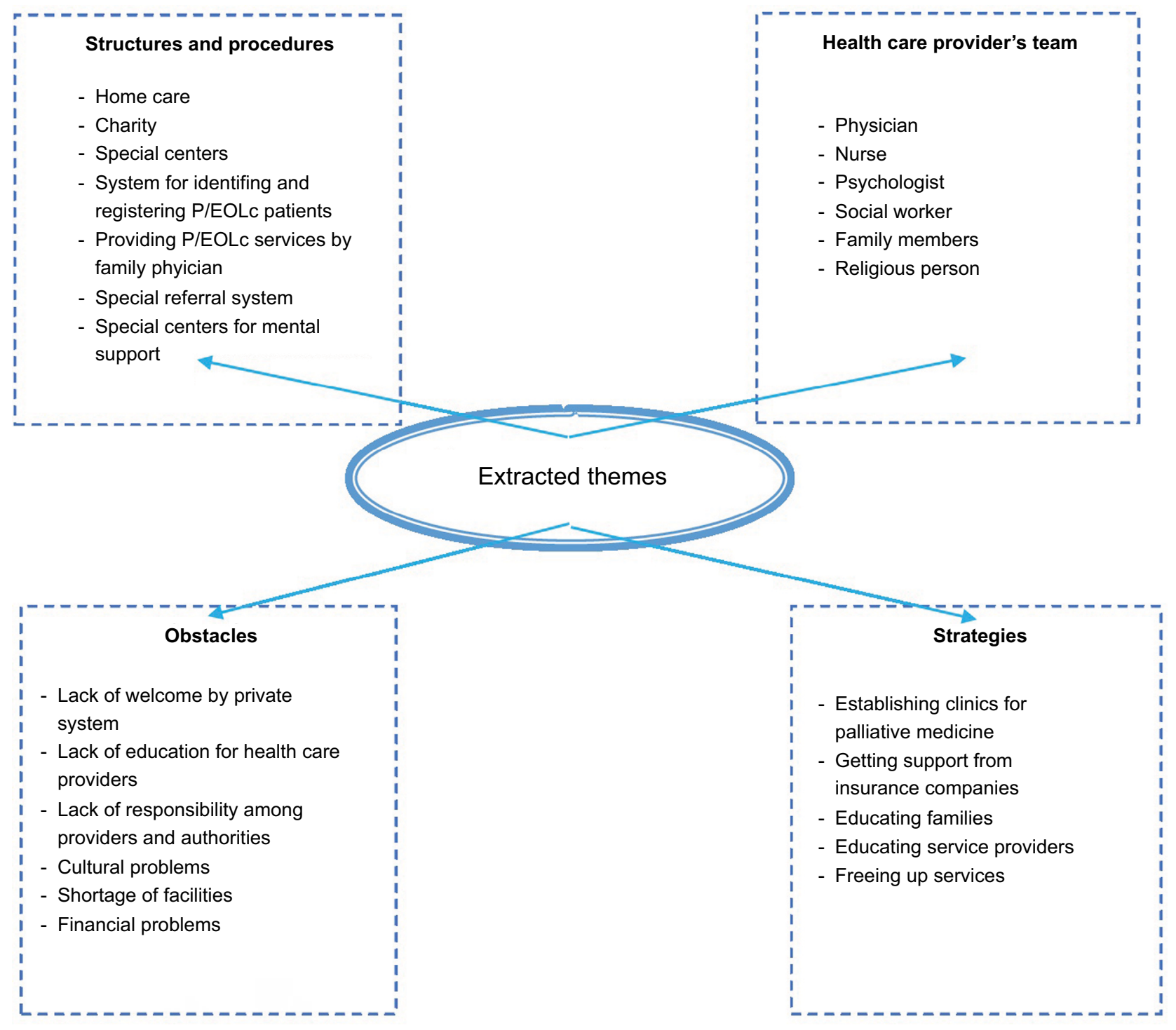

Figure 2 The themes and subthemes extracted while examining the feasibility of organizing P/EOLc in rural areas.

Abbreviation: P/EOLc, palliative end-of-life care.

Table I Suggested structures and procedures for providing EOL services

\begin{tabular}{|l|l|}
\hline Subthemes & Direct quotations from participants \\
\hline Charity & $\begin{array}{l}\text { "I disagree about providing services in places for the aged, since it destroys mental support in these } \\
\text { centers...Creating charities and referring patients with financial problems to these centers...” P3 }\end{array}$ \\
\hline Special centers & $\begin{array}{l}\text { “...Creating special places to care for EOL patients where necessary services are provided...” P7 } \\
\text { “...Some units should be created for their treatment and these patients should be introduced to } \\
\text { these centers and these special centers should manage providing services to them...” P9 }\end{array}$ \\
\hline Home care & $\begin{array}{l}\text { "We can treat these patients medically and mentally at home and they could also be treated in } \\
\text { centers, if necessary...” P9 }\end{array}$ \\
\hline $\begin{array}{l}\text { System for identifying and } \\
\text { registering EOL patients }\end{array}$ & $\begin{array}{l}\text { “...This issue (caring EOL patients) is not well-known in Iran. A system should recognize these } \\
\text { patients. They should have a label and be known as a group.... P8 }\end{array}$ \\
\hline $\begin{array}{l}\text { Providing EOL services by family } \\
\text { physicians }\end{array}$ & $\begin{array}{l}\text { “...It is possible to give responsibility to family physician...Since he/she has a relationship with } \\
\text { these people and is accessible by them...” PI I }\end{array}$ \\
\hline Special referral system & “...Also there should be a special system to refer patients to the related centers...” P7 \\
\hline Special centers for mental supports & “...The need for special centers of mental support is needed for these patients ...” P5 \\
\hline
\end{tabular}

Abbreviation: EOL, end-of-life. 
collected and organized according to the 4 main themes and 17 subthemes (Table 5).

\section{Discussion}

There is clear evidence that EOL patients throughout the world, including Iran, prefer to die at home. Therefore, it is essential that $\mathrm{P} / \mathrm{EOLc}$ should be accessible at facilities that are close to the patients' homes. This requires the integration of P/EOLc into the current Iranian health care system, in keeping with the WHO framework on integrated, peoplecentered health care services. $^{7}$

This qualitative study clearly identified the need for the abovementioned services and the feasibility of starting to offer $\mathrm{P} / \mathrm{EOLc}$ in rural areas, as reported by the main stakeholders and decision makers. Iranian rural FPs reported infrequent participation in caring for EOL patients. They also mentioned that these patients were mainly treated in hospitals and when they returned home there was no comprehensive care program for them, which is consistent with previous Iranian research. ${ }^{8}$ Previous Iranian research found that $\mathrm{P} /$ EOLc patients received all their medical services, according to their diagnosis, in an acute hospital setting with appropriate family members. ${ }^{34,35}$ These patients received very limited care with repeated admissions and discharges following each course of therapy. In other words, these patients experience a lot of inconvenience, ${ }^{36}$ which is made worse by a lack of sufficiently trained medical personnel (ie, nurses, physicians, pharmacists, physiotherapists, and others). ${ }^{37}$ This finding is not specific to Iran, as research has found that P/EOLc services in rural areas are also rare in other parts of the world. ${ }^{15,16,38-40}$

Table 2 Members of the P/EOLc health care providers' team

\begin{tabular}{|l|l|}
\hline Subthemes & Direct quotations from participants \\
\hline Physician & $\begin{array}{l}\text { "A trained team should be responsible for providing services and its members should consist of } \\
\text { a family physician, nurse, psychologist, and family members...” P3 }\end{array}$ \\
\hline Nurse & $\begin{array}{l}\text { "A trained team should be responsible for providing services and its members should consist of } \\
\text { a family physician, nurse, psychologist, and family members...” P3 }\end{array}$ \\
\hline Psychologist & $\begin{array}{l}\text { "A trained team should be responsible for providing services and its members should consist of } \\
\text { a family physician, nurse, psychologist, and family members...” P3 }\end{array}$ \\
\hline Social worker & “...there should also be a social worker in this team, in order to solve financial problems...” PI6 \\
\hline Family members & $\begin{array}{l}\text { "A trained team should be responsible for providing services and its members should consist of } \\
\text { a family physician, nurse, psychologist, and family members...” P3 }\end{array}$ \\
\hline Religious person & “...existence of a clergyman is needed in the group to do religious tasks and consultation...” P5 \\
\hline
\end{tabular}

Table 3 Problems/challenges present in providing P/EOLc

\begin{tabular}{|c|c|}
\hline Subthemes & Direct quotations from participants \\
\hline Financial problems & $\begin{array}{l}\text { "...even in spite of insurance coverage, services are too expensive and patients cannot afford medicines..." P5 } \\
\text { "...Insurance companies don't accept the costs properly and it loads a burden on the people..." PII }\end{array}$ \\
\hline Shortage of facilities & $\begin{array}{l}\text { “...Morphine is difficult to obtain...” PII } \\
\text { “...The most important problem of patients in the last } 1.5 \text { years has been preparing medicines..." PI7 }\end{array}$ \\
\hline Cultural problems & $\begin{array}{l}\text { "...The viewpoint of our society is that a patient should die if he/she cannot be treated. First of all this view } \\
\text { should be changed..." P7 } \\
\text { "Society has the wrong idea about these patients, they think that these patients pay for their sins in this } \\
\text { world..." PI6 }\end{array}$ \\
\hline $\begin{array}{l}\text { Lack of responsibility by } \\
\text { providers and authorities }\end{array}$ & $\begin{array}{l}\text { "Physicians and experts do not accept EOL patients in order to prevent losing their reputation" P2 } \\
\text { "...There is no specific support from authorities" P2 } \\
\text { "...In our centres no one has accepted the responsibility of providing services to these patients..." P4 }\end{array}$ \\
\hline $\begin{array}{l}\text { Lack of standards and } \\
\text { guidelines }\end{array}$ & $\begin{array}{l}\text { "....There is not a single guideline on this topic to support patients mentally and medically. Physicians do things } \\
\text { without a specific plan...." P9 }\end{array}$ \\
\hline $\begin{array}{l}\text { Lack of education health } \\
\text { care providers }\end{array}$ & $\begin{array}{l}\text { "As family physicians we have not been specifically trained about EOL patients, for example we have not been } \\
\text { taught about how to tell the truth to the patient..." P6 } \\
\text { "...We had no specific training. We have just learnt experimentally..." PII }\end{array}$ \\
\hline $\begin{array}{l}\text { Lack of welcome by } \\
\text { private sector }\end{array}$ & $\begin{array}{l}\text { “...A case of a woman with pancreas cancer... had a referral to a private hospital and the hospital did not } \\
\text { accepted her..." P3 }\end{array}$ \\
\hline
\end{tabular}

Abbreviations: EOL, end-of-life; P/EOLc, palliative end-of-life care. 
Table 4 Suggestions for overcoming problems/challenges present in providing P/EOLc

\begin{tabular}{|l|l|}
\hline Subthemes & Direct quotations from participants \\
\hline $\begin{array}{l}\text { Clinics for palliative } \\
\text { medicine }\end{array}$ & $\begin{array}{l}\text { “...As we have clinics for preventative medicine we should also have clinics of palliative } \\
\text { medicine for these patients... which provide services to EOL patients...” P3 }\end{array}$ \\
\hline $\begin{array}{l}\text { Getting support from } \\
\text { insurance companies }\end{array}$ & "Insurance organizations should assign special financial resources to provide these services...” \\
\hline Educating families & $\begin{array}{l}\text { “...Patient's families should be trained about caring for EOL patients...” P6 } \\
\text { “...Alongside physicians and staff, families should also have training courses on behaving } \\
\text { properly with their patients...” P20 }\end{array}$ \\
\hline $\begin{array}{l}\text { Educating service } \\
\text { providers }\end{array}$ & $\begin{array}{l}\text { “...Students should be trained in terms of EOL services...” PII } \\
\text { "Physicians should be specifically trained about behaving properly with these patients...” PI6 }\end{array}$ \\
\hline Freeing up services & “...If EOL services are free, the referral of patients to get services will increase...” PI7 \\
\hline
\end{tabular}

Abbreviations: EOL, end-of-life; P/EOLc, palliative end-of-life care.

Table 5 Main stakeholders of EOLc, regarding the feasibility and modality of preparing P/EOLc in Iranian rural areas

\begin{tabular}{|c|c|c|c|}
\hline Row & Main themes & Subthemes & Quotations \\
\hline 1 & $\begin{array}{l}\text { Family physician } \\
\text { Proper mechanism } \\
\text { for providing } \\
\text { P/EOLc services in } \\
\text { villages }\end{array}$ & $\begin{array}{l}\text { - Integrative structure of } \\
\text { health care network } \\
\text { - Stratifying the services } \\
\text { - Active services of family } \\
\text { physician team in villages }\end{array}$ & $\begin{array}{l}\text { "Our country has a strong healthcare system with triple levels for } \\
\text { providing services and any service could be integrated in it." } \\
\text { "Family physician team has had good success in the country." }\end{array}$ \\
\hline 2 & $\begin{array}{l}\text { Structure of } \\
\text { providing services }\end{array}$ & $\begin{array}{l}\text { - Health center/health house } \\
\text { - Town hospital } \\
\text { - Subspecialty hospital } \\
\text { - University health } \\
\text { information systems } \\
\text { - Social media }\end{array}$ & $\begin{array}{l}\text { "The patient in need should be introduced to the family physician via } \\
\text { oncologist professors." } \\
\text { "A part of services must be provided in the patient's home." } \\
\text { "A curriculum is being prepared and presented for providing services } \\
\text { at their home, general hospital, and university hospital." } \\
\text { "It is possible to deal with complex issues in general hospitals with the } \\
\text { presence of PC specialist and to refer them to university hospitals, } \\
\text { after the coordination of more complex procedures and their required } \\
\text { hospitalization." } \\
\text { "Information about the patient and their treatment should be } \\
\text { continuously recorded and presented using computer systems linked } \\
\text { to the hospital." } \\
\text { "We should use the capacity of social media to send patient } \\
\text { information and coordination with specialist and subspecialist, since we } \\
\text { already use it in many aspects." }\end{array}$ \\
\hline 3 & $\begin{array}{l}\text { Members of the } \\
\text { P/EOLc team in } \\
\text { villages }\end{array}$ & $\begin{array}{l}\text { Physician and nurse, midwife, } \\
\text { social worker, psychologist } \\
\text { and nutritionist }\end{array}$ & $\begin{array}{l}\text { "Thank God members needed in rural areas are already working in the } \\
\text { health system of the country." } \\
\text { "In our country we do not need a religious person in the team." } \\
\text { "Physicians could manage the services very well, as the head of the } \\
\text { team." } \\
\text { "Those persons who do not know anything should be trained." }\end{array}$ \\
\hline 4 & $\begin{array}{l}\text { Sustainable financial } \\
\text { support }\end{array}$ & $\begin{array}{l}\text { - Financial support by health } \\
\text { system } \\
\text { - Coverage by health } \\
\text { insurance } \\
\text { - Cooperation of donors } \\
\text { - Payment of patients }\end{array}$ & $\begin{array}{l}\text { "It is the responsibility of the health system to pay for these services." } \\
\text { "Now insurance companies do not pay for PC in hospital." } \\
\text { "Now there is a good experience in financial support of donors for } \\
\text { infertile couples in the country." } \\
\text { "Donors will definitely help for good and acceptable programs." }\end{array}$ \\
\hline
\end{tabular}

Abbreviation: P/EOLc, palliative end-of-life care.

One of the main themes identified from the FG with FPs was related to the structure and procedures of preparing services, including the necessity of these services, appropriate home care, a specialized referral system, a registration center, and specialized clinics. In other words, according to these FPs, P/EOLc services can be provided within the current structures and processes of the Iranian health care system. The sections of the Iranian health care system that 
will be used include the well organized health network, the FPs and their team, charities, special centers, home care, and so on (strategies and solutions theme). Furthermore, the main stakeholders reported that the FP and their team have the capacity to play the central role in coordinating and controlling the process of caring for rural $\mathrm{P} / \mathrm{EOLc}$ patients inside the current Iranian health care system. These findings are in accordance with previous research ${ }^{9,20,36,41,42}$ and the recently published WHO guidelines, which recommend integrating palliative care into the $\mathrm{PHC}$ system. ${ }^{7}$ Figure 1 presents our suggested model for integrating P/EOLc services into $\mathrm{PHC}$.

The important role of general practitioners and FPs has also been previously reported, ${ }^{43-47}$ as has the necessity of utilizing currently available frameworks and structures..$^{5,48}$ Thus, integrating the new $\mathrm{P} / \mathrm{EOLc}$ program into the strong and effective Iranian health care network ${ }^{27,49,50}$ would appear to be the most efficient and effective strategy. ${ }^{15,25,50-54}$ According to the main stakeholders, it is possible to develop a $\mathrm{P} /$ EOLc program in rural areas using the current national health system, with FPs as the focal point. There are a number of reasons why this approach is appropriate, including the fact that the FP teams consists of an FP, midwife or nurse, pharmacist, and as well as a behvarzes. These teams cover all rural individuals and families and are responsible for 3,000-4,000 people, who are all covered by rural health insurance. ${ }^{30-32}$ Using computerized files, the FP records all periodical visits, home visits, health monitoring, screening results, and conduct referrals to specialized centers. ${ }^{27,55}$

The presence of a physician, social worker, nurse, psychologist, and family members in any team providing $\mathrm{P} /$ EOLc services was considered essential by the participants of both FGs in the present study. In previous research also, the presence of these individuals has been reported to be necessary. ${ }^{43,45,56}$ This finding is also in agreement with recently published WHO guidelines. ${ }^{7}$ However, there are two main issues which must be considered when determining the membership of a team providing $\mathrm{P} / \mathrm{EOLc}$ services in any health system. First, the team providing P/EOLc services should be varied according to the type of services required, patients, context, and other variables. Second, the team providing P/EOLc services should be determined in such a way as to achieve the best cooperation, teamwork, and quality of services. Furthermore, it is important to choose a team leader who can facilitate the coordination of the required services in an efficient manner.

In addition, participants in the first FG stated that providing these services in Iran presented a number of challenges, including financial, cultural, lack of specialist knowledge and skilled personnel, lack of private sector interest, and several similar problems. Moreover, the main stakeholders reported a number of important requirements for any $\mathrm{P} / \mathrm{EOLc}$ program, which were a stratified referral system, quick and efficient exchange of patient records among the physicians involved, a computerized hospital/health information system, as well as the use of social media. The first level of the stratified system would include an upgraded FP team with social worker, physiotherapist, behvarzes, and other providers, as necessary. The second level would involve trained specialist in district polyclinics who would deal with referred patients with complicated problems and finally specialist physicians at university hospitals could be used to deal with very complicated patients, as the third level.

Global experiences have shown that using advanced information technologies to merge patients' records online, at any time or place, is an important requirement for providing services in rural areas. ${ }^{47,57,58}$

Another important concern, raised by the participants of this study, was financing P/EOLc services in the rural areas of Iran. Delegating these services to the charity sector and gaining their support is a common approach that has been used in other parts of the world. ${ }^{18,54}$ Therefore, given the results of this study and the high cost of providing P/EOLc services, as well as the low capacity and capability of the public sector and the lack of interest among insurance companies, it seems that providing these services via charitable entities in Iran is the best method. This approach also fits with WHO recommendations. ${ }^{7}$ However, it is also important that the public and private sectors, including insurance companies, must play a role in supporting these services. These organizations should support the charity entities and provide the appropriate conditions, facilities, and the ability to exchange patient information quickly and easily.

In a qualitative study conducted in Germany, financial obstacles were also identified as the largest barrier to providing these services, ${ }^{59}$ which is a common finding. ${ }^{60,61}$ Finally, it is also important that the Ministry of Health and insurance companies provide some support for the services provided at home.

A recent study of EOL patients, who were treated at university-affiliated hospitals, found that Iranian people were more interested in home care and greatly disliked repeated hospital admissions. It is important to note that the vast majority of people, across the world, prefer to receive their palliative care at home. ${ }^{7}$ Another common complaint was that the patient's family was not kept informed during the 
treatment process. Hence, keeping families informed would be an important function of a dedicated system for dealing with P/EOLc patients in the rural areas of Iran. ${ }^{19}$

Cultural barriers were another major problem mentioned in the first FG. Cultural obstacles have also been identified as a barrier to providing P/EOLc in the USA ${ }^{60}$ Furthermore, research found that ethnic minorities in America use P/EOLc services less often than those from the ethnic majority. ${ }^{62} \mathrm{~A}$ number of other studies in this field have also shown that cultural differences can have a large impact upon the acceptance and use of hospice services. ${ }^{14,17}$ Therefore, according to the results of the present study, and other research conducted in this field, it can be concluded that cultural differences within and across countries should be considered in order to provide appropriate $\mathrm{P} / \mathrm{EOLc}$ services. There are no large cultural obstacles in using the public health system in Iran, but charities can also facilitate this process.

A lack of health care provider training was another obstacle mentioned by the participants, with most participants stating that they had received no specific training about providing $\mathrm{P} / \mathrm{EOLc}$ services. This finding supports previous research on nurses working at a Cancer Center in Tehran, which found that most nurses had received no specific training regarding $\mathrm{P} / \mathrm{EOLc}^{63}$ and with similar research in Iran. ${ }^{55}$ Having the appropriate skills and training, as well as a positive attitude, is an important requirement for adequately providing these services. As in many parts of the world, providing the necessary training for health care providers and students is an effective strategy for addressing this issue. ${ }^{64}$ Fortunately, the WHO recently provided guidelines regarding the education required by the different professionals taking part in P/EOLc. ${ }^{7}$ It seems that integrating these important topics into the curriculum of medical universities, as well as offering training for health care providers at their workplaces, may be an effective approach for improving P/ EOLc services. ${ }^{65,66}$

The participants in the FGs also believed that the patient's family members should play a substantial role in providing P/EOLc services. In line with this, Hauser and Kramer reported that families played the main and most direct role in providing $\mathrm{P} / \mathrm{EOLc}$ to patients. ${ }^{39}$ Thus, the capability and skills of family members caring for patients is also a matter of great importance. Lau et al, who conducted a qualitative study aimed at developing a medication management skills framework for family members caring for EOL patients, also highlighted the importance of family members. In the present study, the key role of family members, particularly their caring skills, was also mentioned. ${ }^{40}$ Therefore, train- ing must be developed and provided for the patient's family members, in relation to their role in supporting and helping EOL patients.

\section{Conclusion}

The most feasible strategy for providing P/EOLc services in the rural areas of Iran would be to base the system around the FP and within the current public health system. This will be comprised of a stratified three-level system, with the FP team as the first level. They will manage the needs of P/ EOLc patients by delivering care directly and referring their patients to the second and third levels, where necessary. The second level will consist of polyclinics at district hospitals and the third level will involve coordinating inpatient care at university hospitals by palliative care specialists. This process will be facilitated using a computerized health information system. Furthermore, involving the charity sector in the financial and social component of P/EOLc would also be recommended. The development of palliative medicine clinics, via the enhanced support of insurance organizations, educating families, empowering team members, and providing services for free may also play an effective role in the advancement of this plan. Therefore, it is suggested that the abovementioned program can be pilot tested in a specific region of Iran. At present, several of the authors are trying to implement this innovative P/EOLc program in Tabriz, Iran, as a pilot program.

\section{Disclosure}

The authors report no conflicts of interest in this work.

\section{References}

1. Naghavi M, Abajobir AA, Abbafati C, et al. Global, regional, and national age-sex specific mortality for 264 causes of death, 1980-2016: a systematic analysis for the Global Burden of Disease Study 2016. Lancet. 2017;390(10100):1151-1210.

2. Global Burden of Disease Cancer Collaboration. Global, regional, and national cancer incidence, mortality, years of life lost, years lived with disability, and disability-adjusted life-years for 29 cancer groups, 1990 to 2016: a systematic analysis for the global burden of disease study. JAMA Oncol. 2018;4(11):1553-1568.

3. Fitzmaurice C. Burden of cancer in the Eastern Mediterranean Region, 2005-2015: findings from the Global Burden of Disease 2015 study. Int J Public Health. 2017:1-14.

4. Vahdatimanesh Z, Zendehdel K, Kbari Sari AA, et al. Economic burden of colorectal cancer in Iran in 2012. Med J Islam Repub Iran. 2017;31:768-773.

5. Rainsford S, MacLeod RD, Glasgow NJ, Phillips CB, Wiles RB, Wilson DM. Rural end-of-life care from the experiences and perspectives of patients and family caregivers: a systematic literature review. Palliat Med. 2017;31(10):895-912.

6. Knaul FM, Farmer PE, Krakauer EL, et al. Alleviating the access abyss in palliative care and pain relief-an imperative of universal health coverage: the Lancet Commission report. Lancet. 2018;391(10128):1391-1454. 
7. WHO. Integrating Palliative Care and Symptom Relief into Primary Health Care: A WHO Guide for Planners, Implementers and Managers. World Health Organization. Geneva, Switzerland; 2018. Available from: http://www.who.int/iris/handle/10665/274559. Accessed December 5, 2018..

8. Rassouli M, Sajjadi M. Palliative care in Iran: moving toward the development of palliative care for cancer. Am J Hosp Palliat Care. 2016;33(3):240-244.

9. Buikstra E, Pearce S, Hegney D, Fallon T. SEAM - improving the quality of palliative care in regional Toowoomba, Australia: lessons learned. Rural Remote Health. 2006;6(1):415.

10. Roudi F, Azadi P, Mesgaran M. Iran's population dynamics and demographic window of opportunity, working paper 4. Stanford Iran 2040 Project, Stanford University, 2017.

11. Rashidian A, Joudaki H, Khodayari-Moez E, et al. The impact of rural health system reform on hospitalization rates in the Islamic Republic of Iran: an interrupted time series. Bull World Health Organ. 2013;91(12):942-949.

12. Azami-Aghdash S, Tabrizi J-S, Mohseni M. Nine years of publications on strengths and weaknesses of Family Physician Program in rural area of Iran: a systematic review. J Anal Res Clin Med. 2016;4(4):182-195

13. Bradley N, Lloyd-Williams M, Dowrick C. Effectiveness of palliative care interventions offering social support to people with life-limiting illness - a systematic review. Eur J Cancer Care. 2018;27(3):e12837.

14. Wilson DM, Justice C, Sheps S, Thomas R, Reid P, Leibovici K. Planning and providing end-of-life care in rural areas. J Rural Health. 2006;22(2):174-181.

15. Fink RM, Oman KS, Youngwerth J, Bryant LL. A palliative care needs assessment of rural hospitals. J Palliat Med. 2013;16(6):638-644.

16. Ceronsky L, Shearer J, Weng K, Hopkins M, Mckinley D. Minnesota Rural Palliative Care Initiative: building palliative care capacity in rural Minnesota. J Palliat Med. 2013;16(3):310-313.

17. Watanabe SM, Fairchild A, Pituskin E, Borgersen P, Hanson J, Fassbender $\mathrm{K}$. Improving access to specialist multidisciplinary palliative care consultation for rural cancer patients by videoconferencing: report of a pilot project. Support Care Cancer. 2013;21(4):1201-1207.

18. Cassel JB, Webb-Wright J, Holmes J, Lyckholm L, Smith TJ. Clinical and financial impact of a palliative care program at a small rural hospital. J Palliat Med. 2010;13(11):1339-1343.

19. Khamenian J, Jabbari-Beyrami H. A Review of End of Life Patients' Experience: A Phenomenological Approach. Tabriz: Tabriz University of Medical Science; 2016.

20. Chisumpa VH, Odimegwu CO, De Wet N. Adult mortality in subSaharan Africa, Zambia: where do adults die? SSM Popul Health. 2017;3:227-235.

21. Robinson CA, Pesut B, Bottorff JL. Issues in rural palliative care: views from the countryside. J Rural Health. 2010;26(1):78-84.

22. Ddungu H. Palliative care: what approaches are suitable in developing countries? Br J Haematol. 2011;154(6):728-735.

23. Groot MM, Vernooij-Dassen MJ, Crul BJ, Grol RP. General practitioners (GPs) and palliative care: perceived tasks and barriers in daily practice. Palliat Med. 2005;19(2):111-118.

24. Howard M, Chalifoux M, Tanuseputro P. Does primary care model effect healthcare at the end of life? A population-based retrospective cohort study. J Palliat Med. 2017;20(4):344-351.

25. Rouhollahi MR, Mohagheghi MA, Mohammadrezai N, et al. Situation analysis of the National Comprehensive Cancer Control Program (2013) in the I. R. of Iran; assessment and recommendations based on the IAEA imPACT mission. Arch Iran Med. 2014;17(4):222.

26. Mobasher M, Nakhaee N, Tahmasebi M, Zahedi F, Larijani B. Ethical issues in the end of life care for cancer patients in Iran. Iran J Public Health. 2013;42(2):188.

27. Takian A, Doshmangir L, Rashidian A. Implementing family physician programme in rural Iran: exploring the role of an existing primary health care network. Fam Pract. 2013;30(5):551-559.
28. Tabrizi JS, Pourasghar F, Gholamzadeh Nikjoo R, Nikjoo RG. Status of Iran's primary health care system in terms of health systems control knobs: a review article. Iran J Public Health. 2017;46(9):1156.

29. Moradi-Lakeh M, Vosoogh-Moghaddam A. Health sector evolution plan in Iran; equity and sustainability concerns. Int J Health Policy Manag. 2015;4(10):637-640.

30. Javanparast S, Baum F, Labonte R, Sanders D, Heidari G, Rezaie S. A policy review of the community health worker programme in Iran. $J$ Public Health Policy. 2011;32(2):263-276.

31. Kalhor R, Azmal M, Kiaei MZ, Eslamian M, Tabatabaee SS, Jafari M. Situational analysis of human resources in family physician program: survey from Iran. Mater Sociomed. 2014;26(3):195.

32. Jabbari H, Bakhshian F, Velayati A, et al. Effectiveness of presence of physician and midwife in quantity and quality of family planning services in health care centers. J Family Community Med. 2014; 21(1): $1-5$

33. Moradi G, Piroozi B, Safari H, Esmail Nasab N, Mohamadi Bolbanabad A, Yari A. Assessment of the efficiency of hospitals before and after the implementation of health sector evolution plan in Iran based on Pabon Lasso model. Iran J Public Health. 2017;46(3):389.

34. Rassouli M, Sajjadi M. Palliative care in Iran: moving toward the development of palliative care for cancer. Am J Hosp Palliat Care. 2016;33(3):240-244.

35. Madjd Z, Afkari M, Goushegir A, et al. The concept of palliative care practice among Iranian General Practitioners. Iran J Cancer Prev. 2012;2:111-116.

36. Rassouli M, Sajjadi M. Cancer care in countries in transition: the Islamic Republic of Iran. In: Silbermann, M, editor. Cancer Care in Countries and Societies in Transition. Springer, Cham. 2016:317-336.

37. Steers J, Brereton L, Ingleton C. Palliative care for all? A review of the evidence in community hospitals. Int $J$ Palliat Nurs. 2007;13(8):392-399.

38. Young RA, Bayles B, Benold TB. Family physicians' perceptions on how they deliver cost-effective care. Fam Med. 2013;45:311-318.

39. Hauser JM, Kramer BJ. Family caregivers in palliative care. Clin Geriatr Med. 2004;20(4):671-688.

40. Lau DT, Kasper JD, Hauser JM, et al. Family caregiver skills in medication management for hospice patients: a qualitative study to define a construct. J Gerontol B Psychol Sci Soc Sci. 2009;64(6):799-807.

41. Lawrenson R, Smyth D, Kara E, Thomson R. Rural general practitioner perspectives of the needs of Māori patients requiring palliative care. $N$ $Z$ Med J. 2010;123(1315):30-36.

42. Rasaf MR, Ramezani R, Mehrazma M, Rasaf MR, Asadi-Lari M. Inequalities in cancer distribution in Tehran; a disaggregated estimation of 2007 incidencea by 22 districts. Int J Prev Med. 2012;3(7):483.

43. Afshar K, Geiger K, Müller-Mundt G. Generalist palliative care for non-cancer patients. Schmerz. 2015:1-11.

44. Mitchell GK. How well do general practitioners deliver palliative care? A systematic review. Palliat Med. 2002;16(6):457-464

45. Minute M, Cozzi G, Plotti C, et al. Children with cancer: a survey on the experience of Italian primary care pediatricians. Ital J Pediatr. 2017;43(1):48.

46. Ankuda CK, Jetty A, Bazemore A, Petterson S. Provision of palliative care services by family physicians is common. J Am Board Fam Med. 2017;30(2):255-257.

47. Wilkes L, Mohan S, White K, Smith H. Evaluation of an after hours telephone support service for rural palliative care patients and their families: a pilot study. Aust J Rural Health. 2004;12(3):95-98.

48. Gott M, Ingleton C, Gardiner C, et al. Transitions to palliative care for older people in acute hospitals: a mixed-methods study. Health Serv Deliv Res. 2013;1(11):1-138.

49. Ramanayake RP, Dilanka GV, Premasiri LW. Palliative care; role of family physicians. J Family Med Prim Care. 2016;5(2):234.

50. Irajpour A, Alavi M, Izadikhah A. Situation analysis and designing an interprofessional curriculum for palliative care of the cancer patients. Int J Med Educ. 2015;14:1047-1056. 
51. Mcrae S, Caty S, Nelder M, Picard L. Palliative care on Manitoulin Island. Views of family caregivers in remote communities. Can Fam Physician. 2000;46:1301-1307.

52. Reymond L, Charles M, Israel F, Read T, Treston P. A strategy to increase the palliative care capacity of rural primary health care providers. Aust J Rural Health. 2005;13(3):156-161.

53. Ansari M, Rassouli M, Akbari ME, Abbaszadeh A, Akbarisari A. Palliative care policy analysis in Iran: a conceptual model. Indian J Palliat Care. 2018;24(1):51.

54. Lloyd-Williams M, Wilkinson C, Lloyd-Williams F. General practitioners in North Wales: current experiences of palliative care. Eur $J$ Cancer Care. 2000;9(3):138-143.

55. Dehnavieh R, Kalantari AR, Jafari Sirizi M, Sirizi MJ. Urban family physician plan in Iran: challenges of implementation in Kerman. Med J Islam Repub Iran. 2015;29:303.

56. Krakauer EL, Rajagopal MR. End-of-life care across the world: a global moral failing. Lancet. 2016;388(10043):444-446.

57. Liu WJ, Hu WY, Chiu YF, et al. Factors that influence physicians in providing palliative care in rural communities in Taiwan. Support Care Cancer. 2005;13(10):781-789.

58. Bakitas MA, Elk R, Astin M, et al. Systematic review of palliative care in the rural setting. Cancer Control. 2015;22(4):450-464.
59. Kaufman J, Forman WB. Hospice and palliative care: an educational intervention for healthcare professionals in a rural community. $\mathrm{Am} \mathrm{J}$ Hosp Palliat Care. 2005;22(6):415-418.

60. Hughes PM, Ingłeton MC, Noble B, Clark D. Providing cancer and palliative care in rural areas: a review of patient and carer needs. $J$ Palliat Care. 2004;20(1):44.

61. Evans R, Stone D, Elwyn G. Organizing palliative care for rural populations: a systematic review of the evidence. Fam Pract. 2003;20(3):304-310.

62. Sach J. Issues for palliative care in rural Australia. Collegian. 1997;4(3):22-27.

63. Kermode-Scott B. Nurturing self-sufficiency. Can Fam Physician. 2000;46:2352.

64. Gessert C, Waring S, Bailey-Davis L, Conway P, Roberts M, Vanwormer J. Rural definition of health: a systematic literature review. BMC Public Health. 2015;15:378.

65. Iranmanesh S, Razban F, Tirgari B, Zahra G. Nurses' knowledge about palliative care in Southeast Iran. Palliat Support Care. 2014;12(3): 203-210.

66. Azami-Aghdash S, Jabbari H, Bakhshian F, et al. Attitudes and knowledge of Iranian nurses about hospice care. Indian J Palliat Care. 2015; 21(2):209.

\section{Journal of Pain Research}

\section{Publish your work in this journal}

The Journal of Pain Research is an international, peer reviewed, open access, online journal that welcomes laboratory and clinical findings in the fields of pain research and the prevention and management of pain. Original research, reviews, symposium reports, hypothesis formation and commentaries are all considered for publication.

\section{Dovepress}

The manuscript management system is completely online and includes a very quick and fair peer-review system, which is all easy to use. Visit http://www.dovepress.com/testimonials.php to read real quotes from published authors. 